\title{
УСЛОВИЯ ПРАВОМЕРНОСТИ НЕОБХОДИМОЙ ОБОРОНЫ, ОТНОСЯЩИЕСЯ К ЗАЩИТЕ
}

\section{TERMS AND CONDITIONS OF DEFENSE NECESSARY DEFENSE}

D. Svirin

Summary. The article examines the institution of necessary defense, namely, the conditions of its legitimacy related to protection. The right to protect their loved ones, themselves and others from criminal attacks is recognized by all civilized peoples and states. The right of citizens to protect their rights and freedoms is one of the fundamental ones enshrined in the Basic Law of the Russian Federation. Such a right was specifically developed in the form of the institution of necessary defense in criminal law. The relevance of this topic is manifested in the fact that the state cannot fully ensure every minute protection of every person from criminal attacks. Therefore, the legislator has provided citizens with the opportunity to protect themselves, to protect others, as well as interests protected by law. However, the questions of the institute of necessary defense and the practice of its application remain quite controversial and debatable. The subject of the research are: legal acts, judicial practice, doctrinal and other sources in the field of the institute of necessary defense. The aim of this work is to study the conditions of lawfulness of the necessary defense related to protection. When writing the work, dialectical, formal-legal, comparative methods were used.

Keywords: criminal law, necessary defense, defense, judicial practice, institution, exceeding limits, responsibility.
$\mathbf{H}$ арушение условий правомерности необходимой обороны и совершение общественно-опасных, противоправных деяний влекут за собой уголовное наказание. Но если соблюдены все условия такой правомерности, то обязанностью государства является непривлечение конкретного лица к уголовной ответственности. Поэтому условия правомерности необходимой обороны имеют очень важное значение, и следует изучить их более подробно.

Так, условиями правомерности необходимой обороны, относящиеся к защите, являются:

1. защищать можно только охраняемые уголовным законом интересы;

2. защита осуществляется путем причинения вреда посягающему;

3. защита не должна превышать пределов необходимой обороны.

\author{
Свирин Данил Андреевич \\ Национальный исследовательский Томский \\ государственный университет \\ svirindanil2015@mail.ru
}

Аннотация. В статье исследуется институт необходимой обороны, а именно условия её правомерности, относящиеся к защите. Право защищать своих близких, себя и других лиц от преступных посягательств, признано всеми цивилизованными народами и государствами. Право граждан на защиту своих прав и свобод является одним из основных, закреплённых в Основном законе Российской Федерации. Такое право получило своё конкретное развитие в виде института необходимой обороны в уголовном законодательстве. Актуальность данной темы проявляется в том, что государство не может в полной мере обеспечить ежеминутную защиту каждого человека от преступных посягательств. Поэтому законодатель предусмотрел возможность гражданам на самозащиту, защиту других лиц, а также охраняемых законом интересов. Однако вопросы института необходимой обороны и практики его применения остаются довольно спорными и дискуссионными. Предметом исследования являются: нормативно-правовые акты, судебная практика, доктринальные и иные источники в сфере института необходимой обороны. Целью данной работы является исследование условий правомерности необходимой обороны, относящиеся к защите. При написании работы были использованы диалектический, формально-юридический, сравнительный методы.

Ключевые слова: уголовное право, необходимая оборона, защита, судебная практика, институт, превышение пределов, ответственность.

1. Первое условие правомерности, относящиеся к защите - круг объектов защиты, т.е. тех охраняемых уголовным законом общественных отношений, которые можно защищать, прибегая к необходимой обороне путем причинения вреда посягающему лицу. Действующая редакция ст. 37 УК РФ не позволяет однозначно решить вопрос об определении круга объектов возможной защиты. Из смысла положений данной статьи, можно сделать вывод, что к таким объектам защиты можно отнести все объекты, указанные в ст. 2 УК РФ: охрана прав и свобод человека и гражданина, собственности, общественного порядка и общественной безопасности, окружающей среды, конституционного строя РФ от преступных посягательств, обеспечение мира и безопасности человечества [1]. Однако в некоторых случаях реализация права на необходимую оборону распространяется не на все объекты, указанные в законе. Например, ст. 306 (Заведомо ложный донос), ст. 310 (Разглашение данных 
предварительного расследования) и т.п. Спорным является и отнесение к таким объектам - чести и достоинства.

Так, Т.Ш. Атабаева пишет, что степень общественной опасности деяния может повлиять лишь на пределы необходимой обороны, но не на ее наличие, поэтому возможна необходимая оборона и от посягательств на честь и достоинство личности [2, с. 20]. В.В. Орехов же отмечает, что необходимая оборона допустима только против таких посягательств на честь и достоинство, если они происходят путем распространения сведений в печатном или рукописном виде, например, при попытке публично вывесить написанные или напечатанные клеветнические сведения [3, с. 73].

Существенно ограничивал объекты возможной защиты при применении необходимой обороны И.С. Тишкевич, который выделял следующие виды посягательств, обороняться от которых возможно, причиняя вред в рамках необходимой обороны: государственные преступления (террористический акт, диверсия, бандитизм); посягательства на собственность (хищение имущества); посягательства на правопорядок (хулиганство); посягательство на жизнь или здоровье; посягательство на личную свободу и половую неприкосновенность [4, с. 19].

В 2014 году широко обсуждался законопроект «Мой дом - моя крепость», который был разработан вице-спикером Государственной думы Лебедевым. Суть его заключается в том, чтобы предоставить гражданам право обороняться от злоумышленников, проникших в дом без страха за последствия. Любые действия, совершенные в собственном доме для защиты своей жизни, здоровья (а также жизни и здоровья близких) и имущества предлагается рассматривать как необходимую оборону [5].

Одной из причин, способствующих разработке такого проекта, явилась оборона тульского бизнесмена. Так, весной 2012 г. в жилище Гегама Саркисяна проникли грабители с целью хищения денежных средств. Злоумышленники, требуя денег, избивали самого Саркисяна, а в другой комнате - женщин и детей. Защищая себя, свою семью и имущество, Гегам совершил убийство трёх посягающих. Первоначально следственные органы возбудили против Саркисяна уголовное дело по п.а ч. 2 ст. 105 УК РФ. Но затем было установлено, что Гегам Саркисян действовал в состоянии необходимой обороны и в результате не был привлечён к уголовной ответственности.

Следует отметить, что Верховный Суд поддержал в части вышеуказанную инициативу. Так, например, В п. 17 Постановления Пленума ВС РФ № 19 говорится, что разрешается применение не запрещенных законом автоматически срабатывающих или автономно действующих средств или приспособлений для защиты охраняемых уголовным законом интересов от общественно опасных посягательств. Если в указанных случаях причиненный посягавшему лицу вред явно не соответствовал характеру и опасности посягательства, содеянное следует оценивать как превышение пределов необходимой обороны. При срабатывании (приведении в действие) таких средств или приспособлений в условиях отсутствия общественно опасного посягательства содеянное подлежит квалификации на общих основаниях.

Есаков Г.А. считает, что подобная чересчур общая формулировка не устраняет пробел, а лишь вносит дополнительные трудности, потому не описывает даже приблизительный круг автоматически срабатывающих или автономно действующих средств защиты [6, с. 17]. Такие приспособления устанавливаются в основном для защиты своего имущества от противоправных посягательств. Но следует иметь ввиду, что сама по себе установка подобных устройств уже представляет определенную общественную опасность для охраняемых уголовным законом интересов. Верно отмечают Зайцев С. А. и Крепышев А. М., что такие устройства должны поддаваться регулировке и контролю со стороны обороняющегося. Такой контроль необходим для учета всех элементов посягательства (количество посягающих, их умысел, орудия нападения и так далее) с целью недопустимости превышения пределов необходимой обороны [7].

В соответствии с ч. 1 ст. 37 УК РФ разрешается причинение любого вреда посягающему, если такое посягательство было сопряжено с насилием, опасным для жизни обороняющегося или другого лица, либо с непосредственной угрозой применения такого насилия. На основании ч. 2 ст. 37 защита от посягательства, не сопряженного с насилием, опасным для жизни обороняющегося или другого лица, либо с непосредственной угрозой применения такого насилия, является правомерной, если при этом не было допущено превышения пределов необходимой обороны.

На мой взгляд, следует определить в уголовном законодательстве, какие именно из правоохраняемых интересов правомерно защищать путем необходимой обороны. То есть, закрепить конкретный перечень возможных объектов защиты и выработать критерии определения пределов возможного причинения вреда.

2. При реализации права на необходимую оборону, вред причиняется исключительно посягающему лицу. Данное условие означает, что недопустимо причинения вреда третьим лицам, не причастных к посягатель- 
ству, что отличает необходимую оборону от крайней необходимости. Также при причинении вреда третьим лицам, которые не участвуют в посягательстве со стороны нападавшего, влечет уголовную ответственность в зависимости от формы вины за умышленные или неосторожные действия, а материальный вред подлежит возмещению.

Вред, причиняемый при необходимой обороне, может заключаться не только в причинении вреда здороВью, лишении жизни посягающего, но и в причинении имущественного вреда. Так, верно, утверждает Заря А. В., что при осуществлении акта необходимой обороны не требуется, чтобы в результате защиты вред был причинён личности нападающего. В ряде случаев вред может быть причинён и его имущественным интересам $[8$, c. 15]. Гражданский кодекс Российской Федерации в ст. 1066 закрепляет: «Не подлежит возмещению вред, причиненный в состоянии необходимой обороны, если при этом не были превышены ее пределы» [9].

В случае если посягательство осуществляется несколькими лицами, то обороняющееся лицо вправе применить к любому из посягающих такие меры защиты, которые определяются характером и опасностью всей группы, в соответствии с п. 12 Постановления Пленума Верховного Суда РФ от 27. 09. 2012 г. № 19 «О применении судами законодательства о необходимой обороне и причинении вреда при задержании лица, совершившего преступление» [10].

Следует отметить, что посягательство может осуществляться и при помощи животных, которые используются в качестве орудия нападения. Каких-либо разъяснений по поводу реализации права на необходимую оборону в таких ситуациях действующее законодательство и правоприменитель не даёт. В таких ситуациях вред непосредственно причиняется животному, от действий которого обороняющее лицо защищается. Так, например, Паше-Озерский считает, что защита от нападения животного, который используется в качестве орудия посягательства, должна рассматриваться как защита от посягательства самого собственника и оцениваться по правилам необходимой обороны. Но если животное используется другим лицом, то защита от нападения в данном случае, по мнению ученого, должна рассматриваться по правилам крайней необходимости [11, с. 65].

Считаю, что если посягательство осуществляется с использованием животных, то следует разрешить обороняющему применять любые средства защиты для отражения такого посягательства. То есть, причинять любой вред нападающему животному. И по результатам такого нападения, собственнику животного не подлежит возмещению вред, причиненный в состоянии необходи- мой обороны. В такой ситуации невозможно оценить, предвидеть действия того или иного животного, какой вред оно способно причинить здоровью и есть ли реальная угроза жизни человека. При этом, для квалификации действий по правилам необходимой обороны не имеет значение, кто является владельцем животного, важным является то, что это животное используется в качестве орудия нападения.

Так, исходя из обстоятельств дела, Н. являлся владельцем взрослой собаки по экстерьеру соответствующей стаффордширскому терьеру, крупной, сильной, мощной и имела агрессивный характер, что подтверждается постоянным нападением на других собак. В состоянии алкогольного опьянения Н., пришёл во двор К. со своей собакой, после чего собака Н., напала на собак К. Последний услышал сильный визг, вышел на крыльцо, произвел предупредительный выстрел в воздух и выдвинул Н. правомерное требование покинуть его двор и увести собаку. Однако Н., напротив, двинулся со своей собакой в сторону К., стоявшему на крыльце. При этом животное, очевидно, находилось в возбужденном состоянии после происшедшего ранее. Это позволяет суду сделать вывод о том, что Н. поощрял действия собаки, то есть натравливал её на К. После этого К. произвёл второй выстрел, в результате которого был причинён вред Н. и его собаке. Производя второй выстрел, К. целился не в Н, а в его собаку, попал в Н. не умышленно, а по неосторожности [12]. Судом было установлено, что причинение вреда нападавшему по неосторожности укладывается в пределы необходимой обороны. Соответственно причинённый вред Н. также не подлежит возмещению на основании ст. 1066 ГК РФ.

3. Защита не должна превышать пределов необходимой обороны, то есть соответствовать характеру и опасности посягательства. Превышение пределов устанавливается только для посягательства, не сопряженного с насилием, опасным для жизни обороняющегося или другого лица, либо с непосредственной угрозой применения такого насилия. В случае если посягательство было сопряжено с насилием опасным для жизни или угрозой применения такого насилия, то разрешается причинение любого вреда посягающему.

В соответствии с обзором практики применения судами положений главы 8 Уголовного кодекса Российской Федерации об обстоятельствах, исключающих преступность деяния, для установления пределов необходимой обороны судами принимались во внимание ряд фактических обстоятельств конкретного дела [13]. Рассмотрим их наиболее подробно:

- соответствие средств защиты и нападения. Пример из судебной практики: гражданин Б. при отказе налить ему спиртное, нанес Г. удар ногой 
в спину, после чего нанес удар по голове в область левого виска. Защищаясь от нападения Г. нанесла Б. кухонным ножом, находящимся у нее в руках, не менее двух ударов в область грудной клетки и брюшной полости, что впоследствии было расценено как тяжкий вред здоровью. Суд признал, что Г. находилась в состоянии необходимой обороны, но предпринятые Г. меры защиты явно не соответствовали характеру и опасности отражаемого посягательства. Суд квалифицирует действия Г. по ч. 1 ст. 114 УК РФ - как умышленное причинение тяжкого вреда здоровью, совершенное при превышении пределов необходимой обороны [14]. В данной ситуации средства защиты явно не соответствовали характеру и опасности нападения;

- внезапность и интенсивность нападения. Так, в ходе конфликта гражданин А. схватил со стола нож и попытался нанести удар снизу вверх гражданину В. Последний левой рукой схватился за лезвие ножа и вырвал его из рук А. и затем нанёс несколько ударов ножом А. С учетом обстановки на месте происшествия, предшествующих событий, а именно того обстоятельства, что А. проявил агрессию, замахнулся ножом, у В. безусловно, имелись основания для применения необходимой обороны. Однако последний избрал несоразмерный интенсивности нападения способ защиты, вооружившись ножом, нанес два удара ножом А., причинив телесные повреждения, повлекшие тяжкий вред здоровью, то есть совершил умышленные действия, явно не соответствующие характеру и опасности посягательства [15].

Подобная ситуация возникла и в данном случае: Гражданин С., попытался нанести удар топором Р. в область головы, однако последнему удалось перехватить руку С. и забрать у него топор. Последний умышленно причинил тяжкий вред здоровью посягавшего, нанеся один удар обухом топора в левую часть головы С. [16]. В описанных ситуациях суд, исходя из обстоятельств дела, счёл, что обороняющиеся избрали несоразмерный интенсивности нападения способ защиты и тем самым превысили пределы необходимой обороны. Интенсивность нападения и защиты по многим делам имеет важное значение. В самом деле, чем интенсивнее действует нападающий, тем большую угрозу для обороняющегося он создает, заставляя его также действовать интенсивнее. В то же время, необходимо учитывать, что понятие интенсивности нападения не всегда применимо для характеристики нападения. Нельзя, к примеру, один выстрел из ружья произвести более или менее интенсивно. Здесь общественная опасность достаточно полно характеризуется средством нападения;
- момент прекращения нападения. Исходя из обстоятельств дела, гражданин Б. подверг И. избиению, а именно нанес не менее трёх ударов кулаками по лицу и телу, а затем достал газовый пистолет, угрожая при этом произвести из него выстрел. И. сумел перехватить данный пистолет у Б., после чего произвел один выстрел из данного пистолета в область груди последнего. После этого, какие-либо обстоятельства, указывающие на продолжение посягательства со стороны Б., отсутствовали. Но гражданин И. вооружившись деревянной палкой продолжил наносить повреждения Б., которые привели к смерти посягающего [17]. Таким образом, после того, как И. удалось забрать пистолет, Б. уже не представлял реальной опасности для его жизни. С учетом изложенного, суд признал виновным И. по ч. 1 ст. 108 УК РФ - убийство, совершенное при превышении пределов необходимой обороны;

- количество посягающих. Пример из судебной практики: гражданину Н. было предъявлено обвинение в том, что он совершил умышленное причинение тяжкого вреда здоровью, опасного для жизни человека, совершенное с применением предмета, используемого в качестве оружия. В соответствии с обстоятельствами дела, ФИО1, ФИО2. и ФИОЗ. в ночное время, без приглашения, по своей инициативе вошли на территорию двора дома Н. и неожиданно совершили нападение на Г. с предметами, используемыми в качестве оружия (лопата и монтировка). Только разбуженный Н. вследствие неожиданности посягательства не мог объективно оценить степень и характер опасности нападения, и у него были основания воспринимать нападение как групповое посягательство, угрожающее жизни и здоровью его и его близких. В процессе обороны Н. наносил удары ножом нападавшим, что было квалифицировано как причинение тяжкого вреда здоровью. В ходе судебного разбирательства было установлено, что Н. действовал в состоянии необходимой обороны и был признан невиновным [18]. В данном случае суд учёл не только нападение группой лиц, но и время посягательства; - физическое развитие посягающего. Например, в результате внезапно возникшего конфликта между Ю. и М., инициированного последним, М. ударил Ю. по лицу и, толкнув на диван, лёг на неё сверху и стал руками душить. Находившаяся в это время в доме мать Ю.-П., попыталась остановить М., пригрозив обратиться за помощью к родственникам. Тогда М. схватил П. за шиворот кофты и повалил на пол, а затем, держа за волосы, стал бить её головой об пол, нанеся не менее 10 ударов, а также не менее 5 раз ударил 
ногой в область живота. При этом Ю. уговорами пыталась прекратить указанные незаконные действия М. в отношении П., но М., не обращая внимания, продолжал наносить удары П., причиняя ей физическую боль. Опасаясь, что М. может причинить вред здоровью или смерть П., Ю., взяв со стола кухонный нож, имея возможность иным образом прекратить противоправные действия М., нанесла этим ножом М. один удар в спину в область правой лопатки, затем нанесла ножом ещё два удара М. в область живота. Ю. была признана виновной в совершении преступления, предусмотренного ч. 1 ст. 114 УК РФ (Умышленное причинение тяжкого вреда здоровью, совершенное при превышении пределов необходимой обороны) [19]. При принятии решения суд обратил внимание на физическое превосходство М. над подсудимой Ю., что подтверждается как показаниями самой подсудимой, так и заключением судебно-медицинской экспертизы № 3557 от 28.12.2017 г. Однако, суд указал, что имелась возможность отразить данное посягательство без угрозы для жизни потерпевшего, то есть без применения ножа, причиняя потерпевшемувред, значительно меньший, чем тот, который она фактически причинила, или обратиться за помощью к другим лицам. Хотя по смыслу ч. 3 ст. 37 УК РФ необходимая оборона может применяться независимо от возможности избежать общественно опасного посягательства или обратиться за помощью к другим лицам или органам власти.

Таким образом, при принятии решения о превышении пределов необходимой обороны, суд учитывает следующие обстоятельства: соответствие средств защиты и нападения, внезапность и интенсивность нападения, момент прекращения нападения, количество посягающих, физическое развитие посягающего. Зачастую человек использует различные предметы для обороны, так как находится в сильном психологическом и эмоциональном стрессе, что не позволяет полностью контролировать сложившуюся ситуацию и иным способом для него преодолеть нападение со стороны посягающего не представляется возможным. Но и злоупотреблять правом на необходимую оборону также не следует, то есть не нужно продолжать причинять вред посягающему, когда угроза дальнейшего нападения явно отсутствует. Так, для правильного решения о наличии или отсутствии превышения пределов, такие обстоятельства должны оцениваться в их совокупности, органическом и неразрывном единстве, что и позволит более полно и всесторонне выяснить вопрос о степени соответствия защиты характеру и опасности посягательства.

\section{ЛИТЕРАТУРА}

1. Уголовный кодекс Российской Федерации от 13.06.1996 г. № 63-Ф3 (ред. от 16.10.2019 г.) // Собрание законодательства РФ.— 1996. — № 25.— Ст. 2954.

2. Атабаева Т. Ш. Необходимая оборона: теория, законодательство, практика применения: Автореф. Дисс. .. канд. юрид. наук / Т. Ш. Атабаева.—- Барнаул, 2004. - 230 c.

3. Орехов В. В. Необходимая оборона и иные обстоятельства, исключающие преступность / В. В. Орехов. — СПб.: Юрид. центр Пресс, 2003.

4. Тишкевич И.С. Защита от преступных посягательств / И. С. Тишкевич.- М.: Госюриздат, 1961.— 70 с.

5. Законопроект «Мой дом — моя крепость» 2014 г. [Электронный ресурс] // URL: https://www.garant.ru/ia/research/544210/. (дата 0бращения: 14.04.2020).

6. Есаков Г. А. Использование предохранительных устройств при защите имущества и необходимая оборона //Уголовное право.—2013.—№ 1.—C. 17-23.

7. Зайцев С.А., Крепышев А. М. 0 правомерности защиты от общественно опасного посягательства // E-Scio. — 2018.

8. Заря А. В. Условия и пределы правомерности необходимой обороны по уголовному праву России: Автореф. Дисс... канд. юрид. наук / А. В. Заря. — М, 2009. - 24 c.

9. Гражданский кодекс Российской Федерации (часть вторая) от 26.01.1996 г. № 14-Ф3 (ред. от 18.03.2019) // Собрание Законодательства РФ.— 1996.№ 5 . - С. 410.

10. Постановление Пленума Верховного Суда РФ от 27 сентября 2012 г. № 19 «0 применении судами законодательства о необходимой обороне и причинении вреда при задержании лица, совершившего преступление» // Бюллетень Верховного Суда Российской Федерации. — 2012.— № 11.

11. Паше-Озерский Н. Н. Необходимая оборона и крайняя необходимость по советскому уголовному праву / Н. Н. Паше-0зерский. - М.: Госюриздат, 1962.$181 \mathrm{c}$.

12. Решение Зейского районного суда Амурской области № 2-1546/2016 2-1546/2016 M-1508/2016 М-1508/2016 от 15.12.2016 г. по делу № 2-1546/2016. URL: https://sudact.ru/regular/doc/2x3GiTAAiyHT/ (дата обращения: 14.04.2020).

13. Обзор практики применения судами положений главы 8 Уголовного кодекса Российской Федерации об обстоятельствах, исключающих преступность деяния (утв. Президиумом Верховного Суда РФ 22 мая 2019 г.) [Электронный ресурс] // Доступ из справ. правовой системы «КонсультантПлюс».

14. Приговор Советского районного суда г. Tомска № 1-27/2019 1-404/2018 от 17. 04. 2019 г. по делу № 1-27/2019. URL: https://sudact.ru/regular/doc/ e0v4ISkZ6jbb/ (дата обращения: 17.04.2020).

15. Приговор Советского районного суда г. Томска № 1-156/2017 от 6.07.2017 г. по делу № 1-156/2017. URL: https://sudact.ru/regular/doc/esyQKleuJpgC/ (дата обращения: 17.04.2020). 
16. Приговор Ленинского районного суда г. Томска № 1-318/2018 от 26. 10. 2018 г. по делу № 1-318/2018. URL: https://sudact.ru/regular/doc/ldkGX33Ugv6t/ (дата обращения: 17.04.2020).

17. Приговор Стрежевого городского суда Томской области № 1-156/2015 от 1. 12. 2015 г. по делу № 1-156/2015. URL: https://sudact.ru/regular/doc/ QSAD37qhc3dL/ (дата обращения: 17.04.2020).

18. Приговор Кувшинского районного суда Тверской области № 1-1/2019 1-37/2018 от 16.04.2019 г. по делу № 1-1/2019. URL: https://sudact.ru/regular/doc/ vQaAbEPauqbC/ (дата обращения: 17.04.2020).

19. Приговор центрального районного суда г. Омска № 1-147/2018 от 16.07.2018 г. по делу № 1-147/2018. URL: https://sudact.ru/regular/doc/lsXcjXdHQgJ4/ (дата обращения: 17.04.2020).

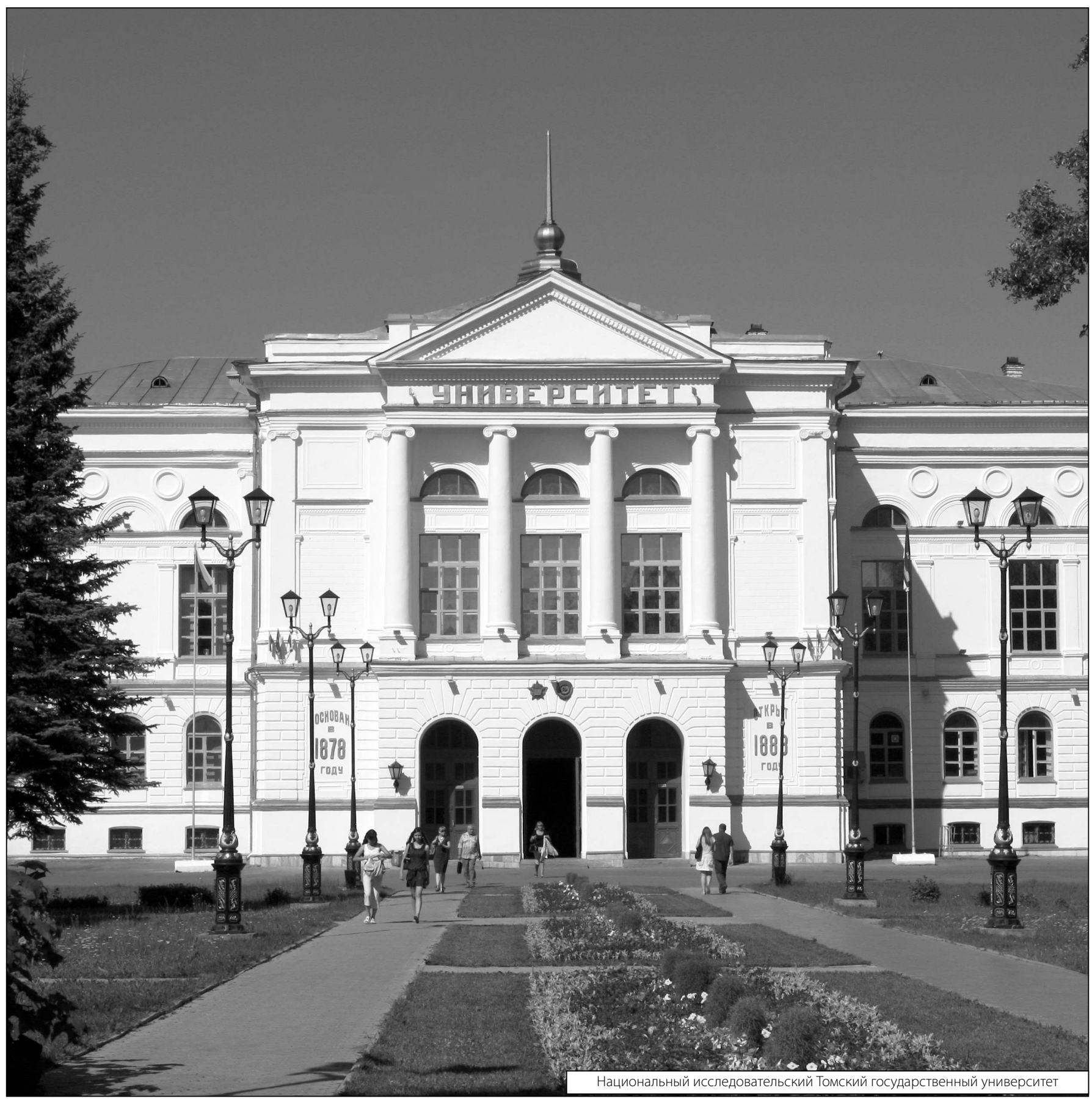

